\title{
Persoonlijke gezondheidscounseling via e-health
}

Hein de Vries, Stan Vluggen

Zowel in de huisartsenpraktijk als in de klinische setting krijgt een gezonde leefstijl en trouw medicijngebruik meer aandacht bij chronische patiënten. Naast face-to-facecounseling kan leefstijl- en medicatieadvies ook via e-health plaatsvinden. E-health-interventies zijn effectief én kosteneffectief gebleken. Wanneer onderbouwd met een gedegen theoretisch gedragsmodel, kan e-health een zinvolle en waardevolle aanvulling zijn op face-to-facecounseling.

Leefstijladvisering voor patiënten met somatische en psychische klachten gebeurt in de huisartsenpraktijk vooral door POH's, die ongeveer in 90\% van de huisartsenpraktijken aanwezig zijn. ${ }^{1}$ Die ondersteuning kan de vorm aannemen van een persoonlijk consult, maar ook plaatsvinden via e-health. Een van de vele definities van e-health luidt: '(...) het gebruik van nieuwe informatie- en communicatietechnologieën, en met name internettechnologie, om gezondheid en gezondheidszorg te ondersteunen.'

Net als alle gezondheidscommunicatie hangt de effectiviteit van e-health-interventies af van de kwaliteit ervan. Belangrijke voorwaarden zijn systematisch ontwikkelen, plannen en evalueren, nauw samenwerken met de doelgroep en - een cruciale voorwaarde - bouwen op een bewezen effectief theoretisch communicatiemodel. ${ }^{3}$ E-health-toepassingen in de huisartsenpraktijk moeten gebaseerd zijn op modellen, of combinaties van modellen, waarvan bewezen is dat ze leefstijl en medicatiegebruik kunnen beïnvloeden.

Veel communicatiemodellen zijn gebaseerd op sociaal-cognitieve theorieën. Deze veronderstellen dat gedrag het resultaat is van de cognities, de ideeën, die iemand heeft over dat gedrag. Men onderscheidt verschillende soorten cognities bijvoorbeeld kennis, risicopercepties, attitude, sociale normen, eigen effectiviteit, actieplanning - en veel modellen verschillen in welke soorten cognities ze selecteren. Zo richt een veelgebruikte theorie van beredeneerd gedrag zich vooral op de motivatie voor een bepaalde gedraging, maar veel minder op hoe je deze motivatie kunt omzetten in handelen. ${ }^{4}$ Het Health Belief Model benadrukt de rol van risicopercepties, weer andere modellen zijn vooral gericht op doelen stellen. ${ }^{5,6}$ Er zijn ook modellen die het gehele proces van gedragsverandering pogen te omvatten door bestaande modellen te combineren en te integreren. Het Integrated-Change Model

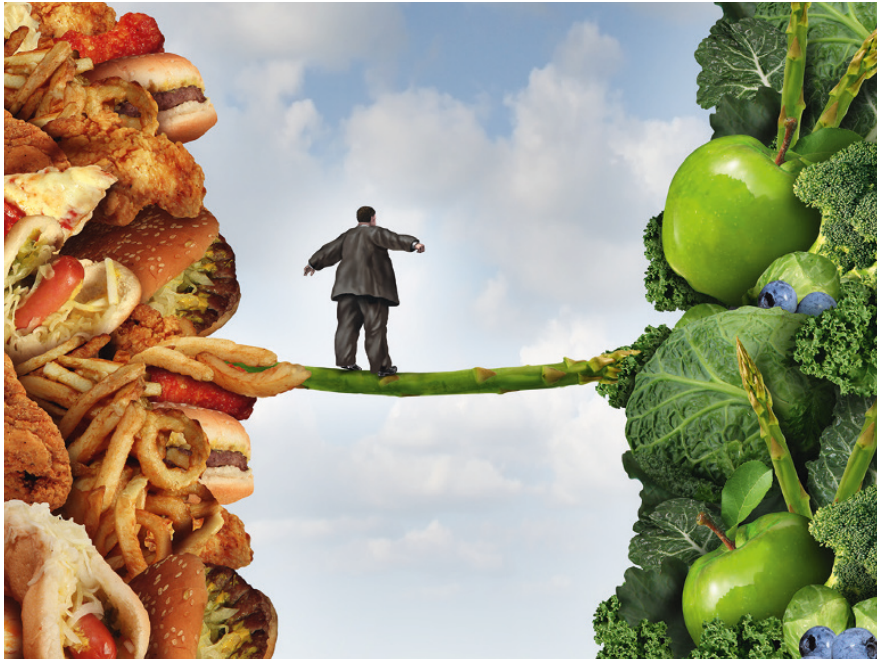

E-health-interventies kunnen een bijdrage leveren aan beter gezondheidsgedrag

Foto: Shutterstock

(I-Change Model) is zo'n integratief model [infographic]. Op basis van het I-Change Model zijn verschillende e-healthinterventies op het gebied van leefstijl en therapietrouw ontwikkeld. ${ }^{7}$ In dit artikel beschrijven we hoe het model kan worden gebruikt voor het geven van persoonlijke feedback en geven we een paar voorbeelden van de toepassing en de effectiviteit ervan.

\section{HET I-CHANGE MODEL}

\section{Premotivationele en motivationele fase}

Het I-Change Model onderscheidt 3 fasen in het proces van gedragsverandering. ${ }^{7}$ De eerste fase is de premotivationele of bewustzijnsfase. ${ }^{8}$ In deze fase wordt een persoon zich ervan bewust dat er een probleem bestaat en dat hij of zij dit probleem ook zelf kan krijgen. Om gemotiveerd te kunnen raken voor gezond gedrag (afstand houden, medicatie innemen) moet iemand zich ervan bewust zijn dat er een probleem is (COVID-19, diabetesklachten). Een patiënt met bijvoorbeeld diabetes type 2 zal alleen goed gemotiveerd zijn om volgens voorschrift insuline te gebruiken als hij of zij weet wat de gevolgen zijn van slecht gebruik én inzicht heeft in zijn of haar eigen manier van gebruiken. Dit laatste noemt men cognizance - correct kunnen inschatten in hoeverre het eigen gedrag 
strookt met het gewenste gedrag. Een patiënt zonder goede cognizance kan ongezond gedrag vertonen terwijl hij ten onrechte denkt dat dat gedrag gezond is. Ook een goede risico-inschatting is belangrijk: de patiënt ziet niet alleen de ernst van het probleem, maar is er ook van overtuigd dat hij zelf risico loopt. Tot slot kunnen cues van buiten (televisie, internet, vrienden) en van het eigen lichaam (klachten) de patiënt bewust maken dat er een probleem is. De [infographic] geeft een voorbeeld waarin patiënten met diabetes type 2 worden aangespoord hun bewegingsgedrag te optimaliseren.

Nadat iemand ervan overtuigd is dat er een probleem is en dat hij of zij ook zelf risico loopt, is de tweede fase in het proces van gedragsverandering de motivatiefase: iemand motiveren om voor gezonder gedrag te kiezen. De intentie die iemand heeft om gedrag uit te voeren, is de uitkomst van 3 factoren:

- iemands attitude ten aanzien van het gedrag (de verwachte voor- en nadelen);

- ervaren sociale steun en normen;

- de eigen effectiviteit (hoe makkelijk of moeilijk zal het zijn het gewenste gedrag ook in lastige situaties vol te houden). ${ }^{9,10}$

\section{Postmotivationele fase: actie, preparatie en coping}

Een positieve intentie is echter nog geen garantie voor gedrag. Daarom staat in de derde fase, de postmotivationele fase, de vertaalslag van het willen (de intentie) naar het doen (het handelen) centraal: hoe faciliteer je het verwezenlijken van een intentie? ${ }^{7}$ Belangrijk is allereerst het maken van een actieplan:

Infographic

\section{I-Change Model}

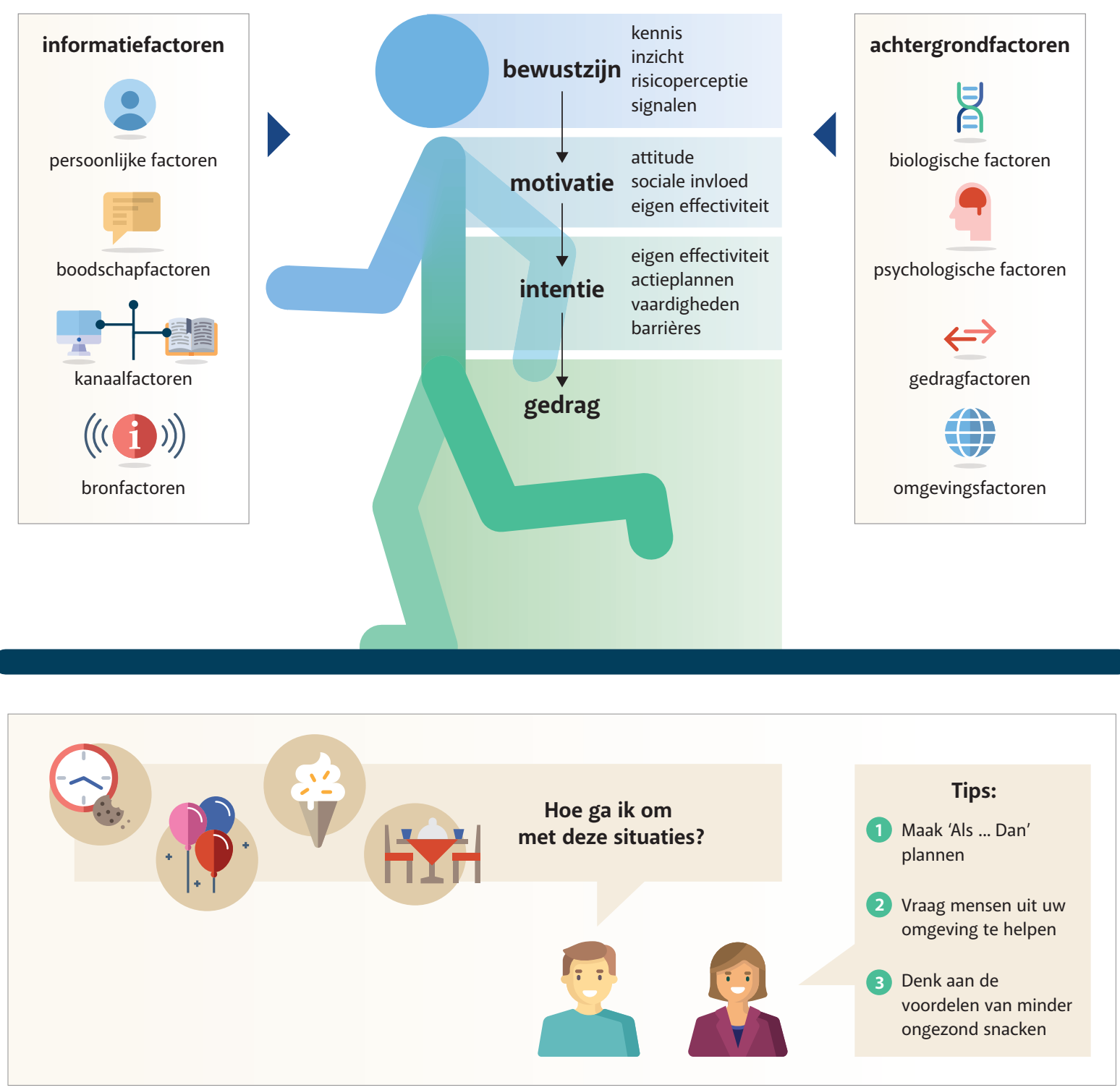




\section{DE KERN}

- Leefstijladviezen worden steeds belangijker in de begeleiding van chronische patiënten.

- E-health-interventies kunnen een waardevolle aanvulling zijn op persoonlijke counseling door de $\mathrm{POH}$, mits ze onderbouwd worden met een degelijke sociaal-cognitieve theorie.

- Het Integrated-Change Model [I-Change Model] is een integratief gedragsmodel dat het hele proces van gedragsverandering omvat en dat inmiddels is geïmplementeerd in verschillende succesvolle e-healthinterventies.

wat is het specifieke gedragsdoel dat iemand wil realiseren en welke acties zijn daarvoor nodig? ${ }^{11}$ Als het actieplan is gemakkt, is het belangrijk om vervolgens preparatieplannen en copingplannen te maken. Wie bijvoorbeeld wil stoppen met roken, zal moeten nagaan hoe dat het beste kan, en een preparatieplan maken. Recentelijk is voor de huisartsenpraktijk een StopWijzer gemaakt (www.stopwijzer.nu), waarbij de patiënt samen met de huisarts of $\mathrm{POH}$ kan nagaan welke stopmethode het beste past. Nieuw, gezond gedrag is soms moeilijk vol te houden, bijvoorbeeld bij stress of verleiding. Het is daarom belangrijk om een inventarisatie te maken van mogelijk lastige situaties en voor elke situatie een copingplan te maken: hoe ga je ermee om? Een goede techniek is het opstellen van een 'implementatie-intentie': 'Als situatie X zich voordoet, dan ga ik Y doen.' ${ }^{12}$ De [infographic] laat een voorbeeld zien waarin deelnemers tips krijgen om de intentie 'minder ongezonde snacks eten' vol te houden in lastige situaties, bijvoorbeeld op een feestje, bij tijdgebrek of tijdens een etentje. Tot slot is het van belang ook voldoende vaardigheden te hebben om het nieuwe gedrag uit te voeren en daadwerkelijk om te gaan met lastige situaties. Een roker die wil stoppen zal voldoende assertief moeten zijn om daadwerkelijk 'nee' te zeggen tegen een aangeboden sigaret.

\section{E-HEALTH-TOEPASSINGEN}

E-health-toepassingen op basis van het I-Change Model gebruiken computer tailoring, advies-op-maat, om elke gebruiker een gepersonaliseerd advies te geven. Daardoor heeft deze meer aandacht voor de boodschap en neemt de effectiviteit toe. ${ }^{13}$ In het volgende voorbeeld onderscheiden we 3 secties, conform de 3 fasen van gedragsverandering in het model. In de eerste sectie krijgt de gebruiker vragen over diens gezondheid en gerelateerde gezondheidsgedragingen. Bij een e-health-toepassing voor diabetes type 2 gaan de vragen bijvoorbeeld over medicatiegebruik en leefstijl, en over de motivatie daarachter. Zo wordt vastgesteld of de patiënt de medicatie al dan niet gebruikt zoals voorgeschreven en of hij of zij gemotiveerd is om het ongewenste gedrag te veranderen, dan wel correct gedrag vol te houden. Daarnaast wordt de cognizance gecontroleerd met behulp van een psychologische vragenlijst, ProMAS. ${ }^{14}$ Op basis van de gegeven antwoorden ontvangt de gebruiker feedback of deze de medicatie wel of niet volgens voorschrift gebruikt, en over het niveau van de motivatie om daar iets aan te doen. Mensen kunnen vaak maar 1 aspect van hun gedrag tegelijk veranderen, dus krijgt de gebruiker de vraag om een gedraging te kiezen die nog niet conform de voorschriften is en dat hij of zij het liefst zou aanpakken. Daarna wordt ingegaan op de kennis over dit gedrag, de risico-inschattingen en de cues die de gebruiker ervaart. $\mathrm{Na}$ het invullen van deze sectie krijg de patiënt persoonlijke feedback op de gegeven antwoorden.

In de tweede sectie krijgt de gebruiker vragen over de verwachte voor- en nadelen van het aanbevolen gezonde gedrag, over de steun die de omgeving daarbij kan bieden en over het vertrouwen in eigen kunnen, dat het nieuwe gedrag ook in moeilijke situaties uitvoerbaar zal zijn. De feedback op de antwoorden in deze sectie legt zo goed mogelijk de voordelen uit waarvan de gebruiker nog niet is overtuigd, geeft aan hoe eventueel meer sociale steun te krijgen is en hoe om te gaan met de moeilijke momenten.

De derde sectie gaat over het maken van actieplannen om het gezondere gedrag uit te voeren, en over plannen voor de moeilijke momenten. De verdeling van de secties over verschillende sessies hangt af van de uitgebreidheid van het programma. ${ }^{15-19}$

\section{WETENSCHAPPELIJK BEWIJS}

In verschillende gerandomiseerde onderzoeken is gekeken of e-health-toepassingen op basis van het I-Change Model gezond gedrag bij mensen inderdaad helpen bevorderen. We bespreken hier kort een aantal Nederlandse onderzoeken. Eén onderzoek betrof een Nederlands online stoppen-met-rokenprogramma. Rokers vulden een vragenlijst in en kregen daarna via de via e-mail eenmalig een gepersonaliseerd advies (de interventiegroep) of een vergelijkbaar, maar algemeen advies (de controlegroep). $\mathrm{Na} 6$ maanden was $8,5 \%$ van de rokers in de e-health-groep gestopt versus 3,4\% in de controlegroep. ${ }^{20}$ Een tweede onderzoek analyseerde de kosteneffectiviteit van 2 uitgebreidere stoppen-met-rokeninterventies. De deelnemers, geworven door 95 POH's, werden gerandomiseerd naar 3 groepen: de e-health-groep kreeg 4 e-health-sessies, de combinatiegroep kreeg na 3 e-health-sessies eenmalige counseling door de $\mathrm{POH}$ gevolgd door een extra telefonisch consult met de $\mathrm{POH}$, de controlegroep kreeg de gebruikelijke zorg. Na 12 maanden was in de e-health-groep 20,5\% gestopt, in de groep met counseling $12,3 \%$ en in de controlegroep 12,6\%. De kosteneffectiviteitsanalyses lieten zien dat de e-health-interventie ook de meest kosteneffectieve was. ${ }^{21}$

Veel e-health-programma's zijn tekstgebaseerd, wat niet altijd de meest effectieve wijze van communicatie. In een stoppenmet-rokenonderzoek is een interventie via video's vergeleken met een tekstgebaseerde interventie en een controleconditie. Het percentage dat was gestopt, was na 6 maanden in de videovariant (20,9\%) significant hoger dan in de tekstvariant 
(17,9\%) en de controlegroep (14,6\%). ${ }^{22}$ De videovariant was ook het meest kosteneffectief. ${ }^{23}$

Het e-healthprogramma 'Mijn Diabetes Profiel' werd ontwikkeld voor patiënten met diabetes type 2 in de eerste of tweede lijn. ${ }^{19}$ Het programma beoogde therapietrouw te verbeteren aan de kernbehandeling: voldoende beweging, lagere consumptie van ongezonde snacks en trouw gebruik van diabetesmedicatie (tabletten en/of insuline). Ter evaluatie werden 478 patiënten gerandomiseerd toegewezen aan de interventieconditie of aan een controleconditie (wachtlijst). De deelnemers in de interventieconditie kregen gepersonaliseerde adviezen via video, afbeeldingen en tekst. Ongepubliceerde resultaten van dit onderzoek laten zien dat na 6 maanden de totale therapietrouw, een combinatie van veranderingen in alle voorgenoemde gedragingen, significant meer verbeterd was in de interventieconditie dan in de controleconditie (effectgrootte $=0,27 ; 95 \%$-BI 0,032 tot 0,$509 ; \mathrm{p}=0,03$ ). In de interventiegroep was de therapietrouw van $78 \%$ van de deelnemers verbeterd, versus $61 \%$ in de controlegroep. Dit effect kwam vooral door gelijkblijvende of lagere calorie-inname uit ongezonde snacks (74 versus 54\%), en beter gebruik van orale en injecteerbare bloedsuikerverlagende medicatie (75 versus 63\%).

\section{CONCLUSIE EN DISCUSSIE}

E-health-interventies kunnen een bijdrage leveren aan beter gezondheidsgedrag, zowel op het gebied van medicatiegebruik als qua leefstijl. Voorwaarde is wel dat ze goede gedragsmodellen gebruiken. Het I-Change Model is een voorbeeld van zo'n gedragsmodel, op basis waarvan effectieve gepersonaliseerde e-health-interventies kunnen worden ontwikkeld. Dat e-health effectief is, impliceert echter niet automatisch dat de interventies ook in de praktijk worden gebruikt. De impact hangt namelijk niet alleen af van het effect, maar ook van het bereik. Er is dus aandacht nodig voor de implementatie in de huisartsenpraktijk. ${ }^{24-27}$ Een factor die die implementatie kan bevorderen is goede training voor POH's en andere zorgprofessionals: hoe kun je e-health het best gebruiken naast de huidige praktijk van face-to-facecounseling en hoe kun je patiënten hiermee vertrouwd maken?26

In een review is aangetoond dat toevoeging van gepersonaliseerde e-health aan het huidige interventiepalet kosteneffectief is. ${ }^{28}$ Zowel in de huisartsenpraktijk als in de klinische setting groeit de noodzaak van actieve aandacht voor leefstijl en medicijngebruik bij chronische patiënten. Gepersonaliseerde e-health kan dan een zinvolle aanvulling zijn op counseling.

\section{LITERATUUR}

1. Van Hassel D, Batenburg R, Van der Velden L. Praktijkondersteuners (POH's) in beeld: Aantallen, kenmerken en geografische spreiding in Nederland. Utrecht: Nivel, 2016.

2. Klein Wolterink G, Krijgsman J. Ordening in de wereld van eHealth. Den Haag: Nictiz, 2012.

3. Bartholomew LK, Parcel GS, Kok G. Intervention mapping: a process for developing theory- and evidence-based health education programs. Health Educ Behav 1998;25:545-63.

4. Ajzen I. The theory of planned behavior. Organizational Behavi- or and Human Decision Processes 1991;50:179-211.

5. Janz NK, Becker MH. The Health Belief Model: a decade later. Health Educ Q 1984;11:1-47.

6. Locke EA, Latham GP. Building a practically useful theory of goal setting and task motivation: A 35-year odyssey. Am Psychol 2002;57:705-17.

7. De Vries H. An Integrated Approach for Understanding Health Behavior; The I-Change Model as an Example. Psychology and Behavioral Science 2017;2:1-6.

8. Weinstein ND. The precaution adoption process. Health psychology: official journal of the Division of Health Psychology, American Psychological Association 1988;7:355-86.

9. Bandura A. Self-efficacy: toward a unifying theory of behavioral change. Psychol Rev 1977;84:191-215.

10. De Vries H, Dijkstra M, Kuhlman P. Self-efficacy: the third factor besides attitude and subjective norm as a predictor of behavioural intentions. Health Educ Res 1988;3:273-82.

11. Van Osch L, Beenackers M, Reubsaet A, Lechner L, Candel M, De Vries H. Action planning as predictor of health protective and health risk behavior: an investigation of fruit and snack consumption. Int J Behav Nutr Phys Act 2009;6:69.

12. Gollwitzer PM. Implementation intentions: Strong effects of simple plans. Am Psychol 1999;54:493-503.

13. Lustria ML, Cortese J, Noar SM, Glueckaluf RL. Computer-tailored health interventions delivered over the web: Review and analysis of key components. Patient Educ Couns 2009;74:156-73.

14. Vluggen S, Hoving C, Schaper NC, De Vries H. Psychological predictors of adherence to oral hypoglycaemic agents: an application of the ProMAS questionnaire. Psychol Health 2020;35:387-404.

15. De Vries H, Logister M, Krekels G, Klaasse F, Servranckx V, van Osch L. Internet based computer tailored feedback on sunscreen use. J Med Internet Res 2012;14:e48.

16. Voncken-Brewster V, Moser A, Van der Weijden T, Nagykaldi Z, De Vries H, Tange H. Usability evaluation of an online, tailored self-management intervention for chronic obstructive pulmonary disease patients incorporating behavior change techniques. JMIR Res Protoc 2013;2:e3.

17. Van der Wulp NY, Hoving C, Eijmael K, Candel MJ, Van Dalen W, De Vries H. Reducing alcohol use during pregnancy via health counseling by midwives and internet-based computer-tailored feedback: a cluster randomized trial. J Med Internet Res 2014;16:e274.

18. Walthouwer MJ, Oenema A, Soetens K, Lechner L, De Vries H. Systematic development of a text-driven and a video-driven web-based computer-tailored obesity prevention intervention. BMC Public Health 2013;13:978.

De volledige literatuurlijst staat bij dit artikel op www.henw.org.

De Vries H, Vluggen S. Persoonlijke gezondheidscounseling via e-health. Huisarts Wet 2020;63[12]:50-3. D0l:10.1007/s12445-0200930-0.

Universiteit Maastricht, Care and Public Health Research Institute [CAPHRI], Vakgroep Gezondheidsbevordering, Maastricht: prof. dr. H. de Vries, hoogleraar Gezondheidscommunicatie; dr. S. Vluggen, postdoc onderzoeker, stan.vluggen@maastrichtuniversity.nl. Mogelijke belangenverstrengeling: niets aangegeven. 